\title{
Changes in mood states during the preparation period of the world's top junior tennis player
}

\author{
Dario Novak (University of Zagreb, Croatia) \& Tijana Cirkovic (Serbian Institute of Sport, Serbia) \\ ITF Coaching and Sport Science Review 2015; 65 (23): 28-31
}

ABSTRACT

Conditioning preparation plays a key role in tennis. However, conditioning is usually marked by a fairly large training volume. Early identification of youth tennis players with serious emotional disorders is critical for avoiding overtraining. In the present study we investigated the changes in mood states during the preparation period of a top junior tennis player. The Brunel Mood Scale, consisting of 6 subscales with a 5-point rating scale to assess levels of mood states was used at 8 PM each night, and then again the following morning (8 AM). It can be concluded that specific mood factors increase and decrease in accordance with alterations in training intensity and period of the day.
Key words: emotions, intensity, training, assessment Received: 19 December 2014 Accepted: 25 January 2015 Corresponding author: Dario Novak Email: dario.novak@kif.hr

\section{INTRODUCTION}

On-court tennis training and match play involves prolonged, physically demanding activities that push the body to it's limits resulting in substantial elevation of physiological and perceptual strain and reduced contractile function. Tennis players are expected to be in optimal condition for a large number of tournaments during the year, and there is no time for the "long" preparation period (Duffield, Murphy, et al., 2014). That's why all the measurements that provide a quick performance feedback are very beneficial. Early identification of youth tennis players with serious emotional disorders is critical for avoiding overtraining. Emotions are shown to have great influence on an athlete's performance. Extensive research into the role of anxiety in sport performance has already been conducted. Still, there are a wide range of emotional states that have not been reviewed to the same extent. Mood states are different from specific emotions in that they are more enduring and less intense feeling states, but their effect on sports performance is thought to be substantial (Hagger and Chatzisarantis, 2005). Fewer studies to date have focused on mood states among tennis players. This study therefore investigates the changes in mood states during the preparation period of a top junior tennis player.

\section{METHODS AND PROCEDURES}

The subject in this study is an elite junior female player who was the number one ranked junior in the world at the time this study was conducted (ITF Ranking list, July, 2014). Her parents gave consent in accordance with the requirements of the Declaration of Helsinki. The subject had the following characteristics: age, 17; body mass index, 21.83; body height, $174 \mathrm{~cm}$, ranking on the ITF world junior list, 1 . The study was performed during her summer off-season (July 14 - Aug 3 2014). The preparation period was marked by a fairly large amount of conditioning trainings (i.e., jogging, endurance, tennis, strength and power trainings) (Table 1).

\begin{tabular}{|c|c|c|c|}
\hline & Week 1 & Week 2 & Week 3 \\
\hline $\begin{array}{l}\text { Technical and } \\
\text { tactical training }\end{array}$ & $\begin{array}{c}\text { o min } \\
\text { o sessions }\end{array}$ & $\begin{array}{c}500 \text { min } \\
6 \text { sessions }\end{array}$ & $\begin{array}{c}450 \text { min } \\
5 \text { sessions }\end{array}$ \\
\hline $\begin{array}{l}\text { Neuromuscular } \\
\text { training }\end{array}$ & $\begin{array}{l}525 \text { mins } \\
5 \text { sessions }\end{array}$ & $\begin{array}{c}600 \text { min } \\
6 \text { sessions }\end{array}$ & $\begin{array}{c}180 \text { min } \\
2 \text { sessions }\end{array}$ \\
\hline Endurance training & $\begin{array}{c}315 \text { mins } \\
4 \text { sessions }\end{array}$ & $\begin{array}{c}210 \mathrm{~min} \\
4 \text { sessions }\end{array}$ & $\begin{array}{c}180 \\
4 \text { sessions }\end{array}$ \\
\hline $\begin{array}{c}\text { Number of } \\
\text { training sessions }\end{array}$ & 9 & 16 & 11 \\
\hline Number of matches & 0 & 2 & 4 \\
\hline
\end{tabular}

Table 1. The 3-weeks preparation period summary.

The 24 items Brunel Mood Scale, comprise the following six mood subscales: tension, depression, anger, vigor, fatigue and confusion. Each subscale contains four items. A 5-point rating scale to assess levels of mood states was used at 8 PM each night, and then again the following 


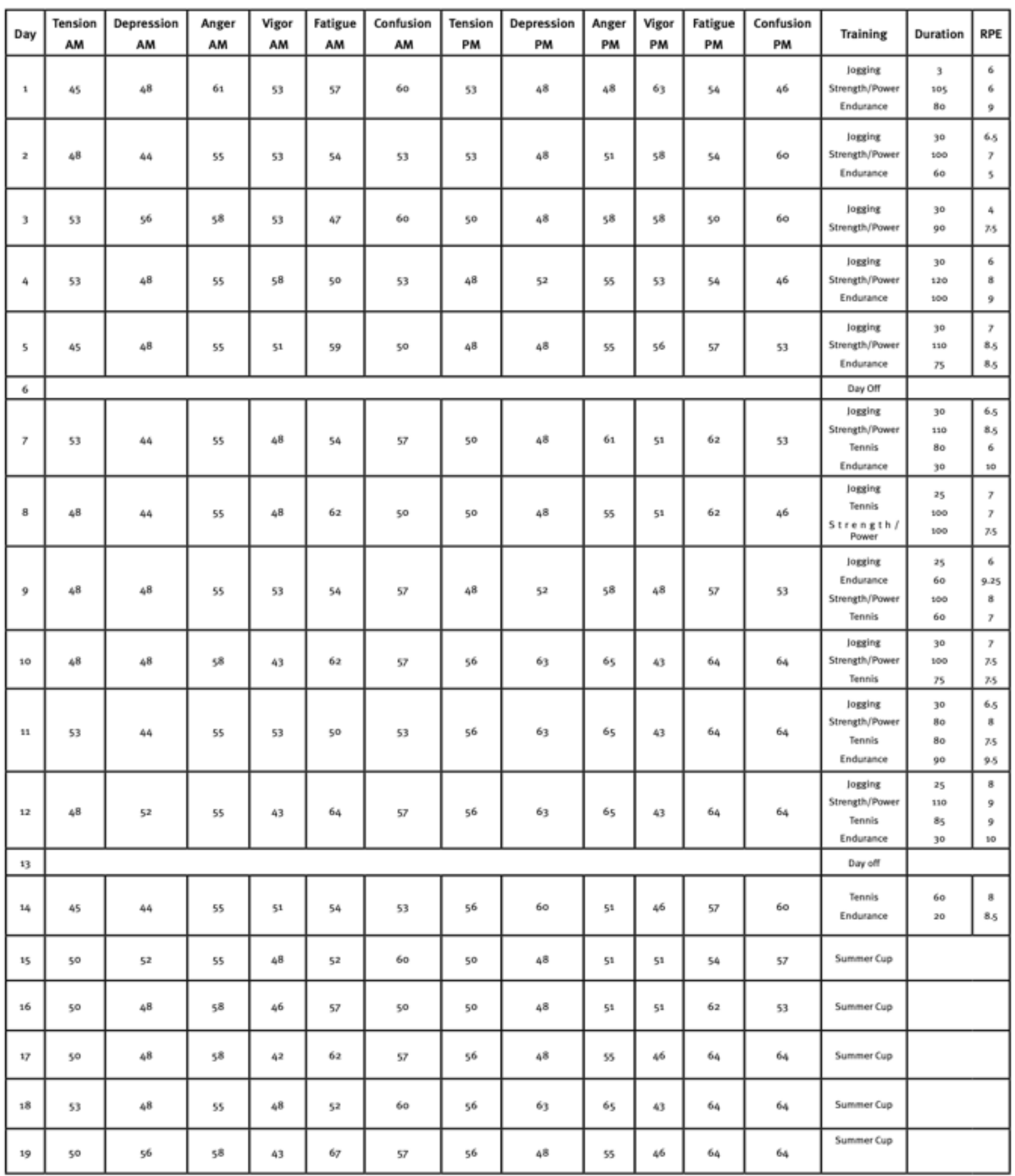


feel right now?" respondent indicated whether she experienced such feelings on a 5-point scale $(0=$ not at all, 1 = a little, 2 = moderately, 3 = quite a bit, 4 = extremely). When responses from the four items in each subscale are summed, a subscale score in the range $0-16$ is obtained. Raw scores were converted to standard scores (T-scores) (Terry, 2000).

\section{RESULTS}

The specific mood factors increase and decrease in accordance with alterations in training intensity and period of the day. There are more negative moods recorded towards the end of the preparation period. Trends show that the athlete experiences a more positive mood in the morning while showing tendency to have a more negative mood in the evening. Negative moods with the presence of tension, depression, anger and fatigue are more present at the end of the day which is filled with jogging, strength and power, tennis and endurance sessions than in the morning before all of these activities. Fatigue seems to be very high and constant during the whole preparation period. Interestingly, the effect of a negative mood seems to be more present in the period with the matches (Table 2).

\section{DISCUSSION}

The preparation period of a top junior player provided a unique opportunity to evaluate mood changes that occur during prolonged high intensity activities. The objective of this study was to investigate the changes in mood states during the preparation period of a top junior tennis player. As a result, the magnitude of the increased training volume influenced and affected changes in the young tennis player's mood. There are many examples of athletes who perform at optimal levels during training but are unable to repeat those same peak levels of performance when competing. Usually it is said that emotions are something that distinguishes those who are able to show their best when needed and those who can't. Our emotions are always present while we are doing something, so there is no doubt that they can have an effect in sports as well. The literature suggests that there is a significant correlation between mood states and training intensity. It was suggested also that mood changes tracking may be used to indicate those athletes predisposed to the condition long before symptoms of poor performance and prolonged fatigue are observed (Pierce, 2002). Morgan and colleagues have demonstrated the efficacy of monitoring mood state changes in response to training volume as a marker for overtraining among endurance athletes (Morgan, Brown, et al., 1987). Previous research has suggested that subscores of Fatigue and Vigor may show changes relatively early during high training volume, while Tension, Depression and Anger seem to respond to chronic high training volume (Morgan, Costill, et al., 1988; O'Connor, Morgan, et al., 1991). Our finding shows that Fatigue changed relatively early during high training volume but Vigor stayed constant. Tension, Depression, and Anger seem to respond to chronic high training volume especially in the evening. Progressive increases in training load are routinely imposed in endurance training programs and are believed to be effective in achieving optimal conditioning among athletes. It is also well documented, however, that the stress of overtraining may lead to the development of "staleness" (Hooper, MacKinnon, et al., 1997; Pierce, 2002). While symptoms may vary across individuals, staleness is generally characterised by a delay in recovery from training sessions as well as decreased performance during training or competition (Ryan, 1983). Recognition of physiological or psychological factors contributing to the development of staleness, therefore, would be of particular value for those administering training routines. This type of mood changes tracking using the Brunel Mood Scale could be very beneficial for fitness and tennis coaches for avoiding symptoms of decreased performance, staleness or overtraining. It is, however, also worth pointing out that sample size in this case study is too small to produce a clear picture but measuring these changes during the preparation period is worthwhile and beneficial.

\section{CONCLUSION}

Tennis today requires a tennis player to have a very high level of readiness. At the same time, one must be aware that the stress of overtraining may lead to the development of "staleness." The Brunel Mood Scale could be a very beneficial tool to track mood states of young players especially during high intensity sessions. Additional studies are needed to identify interventions that can increase performance with the ultimate goal of achieving healthier athletes.

\section{REFERENCES}

Duffield, R., Murphy, A., Kellett, A. Reid, M. (2014). Recovery From Repeated On-Court Tennis Sessions: Combining Cold-Water Immersion, Compression, and Sleep Interventions. International Journal of Sports Physiology and Performance, 9:273282.https://doi.org/10.1123/ijspp.2012-0359

Hagger, M., Chatzisarantis, N. (2005). Social Psychology of Exercise and Sport. McGraw-Hill International.

Hooper, S.L., MacKinnon, L.R., Hanrahan, S. (1997). Mood states as an indication of staleness and recovery. International Journal of Sport Psychology, 28, 1-12.

Morgan, W.P., Brown, D.R., Raglin, J.S, O'Connor, P.J., Ellickson, K.A. (1987). Psychological monitoring of overtraining and staleness. British Journal of Sports Medicine, $21,107-$ 114.https://doi.org/10.1136/bjsm.21.3.107

Morgan, W.P., Costilld, D.L., Flynn, M.G., Raglin, J.S., O'Connor, P.J. (1988). Mood disturbance following increased training in swimmers. Medicine and Science in Sports and Exercise, 20, 408414.https://doi.org/10.1249/00005768198808000-00014

O'Connor, P.J., Morgan, W.P., Raglin, J.S. (1991). Psychobiological effect of 3 days of increased training in female and male swimmers. Medicine and 
Science in Sports and Exercise, 23, 10551061.https://doi.org/10.1249/00005768-

199109000-00010

Pierce, E.F. (2002). Relationship between training volume and mood states in competitive swimmers during a 24weeek season. Perceptual and Motor Skills, 94, 1009-

1012.https://doi.org/10.2466/pms.2002.94.3.1009

Ryan, A.J. (1983). Overtraining in athletes: a roundtable. The physician and Sportsmedicine, 11, 93100.https://doi.org/10.1080/00913847.1983.1170 8610

Terry, P. C. (2000). An overview of the relationship between mood and performance in sport. Australian Journal of Psychology, 52, S115.

RECOMMENDED ITF TENNIS ICOACH CONTENT (CLICK BELOW)

TennisOicoach

RECOMMENDED ITF TENNIS ACADEMY CONTENT (CLICK BELOW)

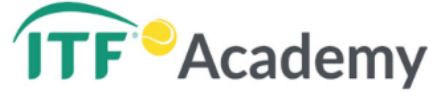

Copyright (c)_Dario Novak \& Tijana Cirkovic 2015

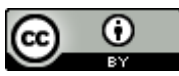

This text is under a Creative Commons BY 4.0

license

You are free to Share - copy and redistribute the material in any medium or format - and Adapt the content - remix, transform, and build upon the material for any purpose, even commercially under the following terms:

Attribution: You must give appropriate credit, provide a link to the license, and indicate if changes were made. You may do so in any reasonable manner, but not in any way that suggests the licensor endorses you or your use.

CC BY 4.0 license terms summary

CCBY 4.0 license terms 